\title{
СИНТЕЗ ОКТЕНІДИНУ ГЕКСАФТОРОСИЛІКАТУ - НОВОГО ПОТЕНЦІЙНОГО КАРІЄСПРОФІЛАКТИЧНОГО І АНТИБАКТЕРІАЛЬНОГО АГЕНТА
}

\author{
() В. О. Гельмбольдт, В. Ю. Анісімов, І. О. Шишкін \\ Одеський національний медичний університет \\ vgelmboldt@te.net.ua
}

\begin{abstract}
Мета роботи. Здійснити синтез октенідину гексафторосилікату як потенційного карієспрофрілактичного антибактеріального препарату.

Матеріали і методи. Вихідні реагенти, октенідину дигідрохлорид і кремнеотороводнева кислота є комерційно доступними реактивами. ІЧ-спектри поглинання реєстрували на спектрофотометрі Spectrum BX II FT-IR System (Perkin-Elmer), мас-спектри FAB - спектрометрі VG 7070 (VG Analytical), спектри ЯMP ${ }^{1} \mathrm{H},{ }^{19} \mathrm{~F}-$ на спектрометрі Varian Gemini-400. Термогравіметричний аналіз проводили на дериватоградрі Q-1500 D системи F. Paulik - J. Paulik - L. Erdey.

Результати й обговорення. Одержано октенідину гексасторосилікату моногідрат на основі реакції іонного обміну між метанольним розчином октенідину дигідрохлориду і кремнестороводневою кислотою. Склад і іонна будова синтезованої сполуки підтверджено методами ІЧ-, ЯМР ${ }^{1} \mathrm{H},{ }^{19} \mathrm{~F}$-спектроскопії, мас-спектрометрії. Термоліз комплексу супроводжується процесами дегідратації і деструкції з подальшим окисленням фррагментів катіону.

Висновки. Синтезовано октенідину гексафторосилікату моногідрат, нове похідне октенідину, що становить інтерес як потенційний карієспрофрілактичний і антибактеріальний засіб.
\end{abstract}

Ключові слова: карієспрофрілактичні агенти; октенідину гексафрторосилікат; синтез; спектральні характеристики.

Вступ. На сьогодні фрторидні препарати займають лідируючі позиції в арсеналі засобів лікування і профрілактики карієсу [1]. Сьогодні як перспективні антикарієсні агенти активно вивчають гексафторосилікат амонію [2-4] і гексасрторосилікати органічних «онієвих» катіонів [5-9], що демонструють певні переваги порівняно з традиційно використовуваними фрторидними сполуками. Для посилення карієспроорілактичної дії фторидної компоненти до складу лікарських засобів зазвичай вводять бактерицидні агенти (похідні біс-гуанідину, четвертинні амонієві солі - цетилпіридинію хлорид, фенольні похідні - триклозан) [10], що пригнічують розвиток кислотоутворюючої мікрофрлори порожнини рота. Раніше було показано, що гексафрторосилікати з бактерицидними катіонами хлоргексидину, полігексаметиленгуанідинію [6] і цетилпіридинію [7] есрективно зменшують кількість і глибину каріозних уражень зубів у тварин з одночасним суттєвим поліпшенням біохімічних показників пульпи зубів [8]. До числа сучасних антисептиків, які використовують у фрармацевтичній практиці і продовжують активно вивчати, входить октенідин - N,N'-(1,10-декандил-ді-1[4H]-піридин-4-іліден)-біс(1-октамін) дигидрохлорид [11], що має певні аналогії в будові і характері антимікробної дії з цетилпіридинію хлоридом. Мета роботи - синтез та ідентифрікація нового антикарієсного і бактерицидного агента - октенідину гексафторосилікату.
Матеріали і методи. ІЧ-спектри поглинання реєстрували на спектрофотометрі Spectrum BX II FT-IR System (Perkin-Elmer) (область 4000 - $350 \mathrm{~cm}^{-1}$, зразки у виді таблеток з KBr). Мас-спектри FAB реєстрували на спектрометрі VG 7070 (VG Analytical) (десорбцію іонів із поверхні рідкої фрази здійснювали пучком атомів аргону з енергією 8 кеВ, як матрицю використовували м-нітробензиловий спирт). Спектри ЯМР ${ }^{1} \mathrm{H},{ }^{19} \mathrm{~F}$ записували на спектрометрі Varian Gemini-400 (400, 376,4 Мгц відповідно, розчинник ДMCO-d ${ }^{6}$, внутрішні стандарти - ТMC, CFCl $)$. Термогравіметричний аналіз проводили на дериватографі Q-1500 D системи F. Paulik - J. Paulik - L. Erdey (платинові тиглі, наважка речовини 150 мг, інтервал температур 20 - $1000{ }^{\circ} \mathrm{C}$, швидкість нагрівання зразка 10 град/хв, еталон - прожарений оксид алюмінію). Вміст азоту визначали за К'єльдалем [12], кремнію фоотоколориметричним методом [13].

Методика синтезу октенідину гексафторосилікату моногідрату $\left(\mathrm{C}_{36} \mathrm{H}_{62} \mathrm{~N}_{4}\right) \mathrm{SiF}_{6} \cdot \mathrm{H}_{2} \mathrm{O}$ (I). Синтез гексафторосилікату здійснювали шляхом реакції іонного обміну між метанольним розчином октенідину дигідрохлориду (ОДГХ, Wuham Jason Biotech Co., Ltd., Китай) і розчином 45 \% кремнесттороводневої кислоти (мольне співвідношення ОДГХ: $\mathrm{H}_{2} \mathrm{SiF}_{6}=1: 3$ ). Реакційну суміш витримували при кімнатній температурі до випару розчинників з утворенням кристалічного

ISSN 2312-0967. Pharmaceutical review. 2017. № 3 
Синтез біологічно активних сполук

Synthesis of biologically active compounds

продукту (білий з жовтим відтінком) з практично кількісним виходом.

Результати й обговорення. Склад виділеної сполуки встановлений за даними елементного аналізу.

Знайдено, \%: N - 8,22; Si - 4,19.

Для $\left(\mathrm{C}_{36} \mathrm{H}_{62} \mathrm{~N}_{4}\right) \mathrm{SiF}_{6} \cdot \mathrm{H}_{2} \mathrm{O}$ (I) обчислено, \%: N - 7,86; $\mathrm{Si}-3,94$.

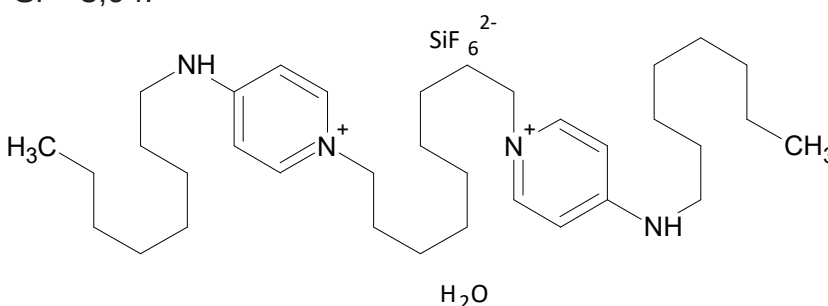

Mac-спектр FAB I: $\left[\mathrm{C}_{36} \mathrm{H}_{62} \mathrm{~N}_{4}\right]^{2+} \cdot(\mathrm{m} / \mathrm{z}=550, \mathrm{I}=$ $7,52 \%),\left[\mathrm{C}_{36} \mathrm{H}_{62} \mathrm{~N}_{4}+\mathrm{H}\right]^{2+} .(\mathrm{m} / \mathrm{z}=551, \mathrm{l}=100 \%)$.

ІЧ-спектр I ( $\left(\mathrm{cm}^{-1}\right): 3514,3211,3130,3102,3038$ $[\mathrm{v}(\mathrm{NH}), \mathrm{v}(\mathrm{OH})], 2928\left[\mathrm{v}_{\mathrm{as}}\left(\mathrm{CH}_{2}\right)\right], 2853\left[\mathrm{v}_{\mathrm{s}}\left(\mathrm{CH}_{2}\right)\right], 1654$ $[\mathrm{V}(\mathrm{C}=\mathrm{N})], 1586,1557,1519\left[\mathrm{v}_{\text {кільця }}\right], 1463\left[\delta_{\mathrm{s}}\left(\mathrm{CH}_{2}\right)\right], 1389$ $\left[\delta_{\mathrm{s}}\left(\mathrm{CH}_{3}\right)\right], 1221,1190[\delta(\mathrm{CH})], 737\left[\mathrm{~V}(\mathrm{SiF})+\rho\left(\mathrm{CH}_{2}\right)\right]$, $482,443\left[\delta\left(\mathrm{SiF}_{2}\right)\right]$.

Спектр ${ }^{1} \mathrm{H}$ ЯМР катіону октенідину у складі I, $\delta$, м.ч.: 8.69 (2H, с, NH), 8.28 (д, J $7.8 \mathrm{~Hz}, 2 \mathrm{H}$, піридин), 8.11 (д, J $6.4 \mathrm{~Hz}, 2 \mathrm{H}$, піридин), 6.89-6.91 (м, 4H, піридин), 4.09 (т, J $\left.6.8 \mathrm{~Hz}, 4 \mathrm{H},{ }^{1} \mathrm{CH}_{2}\right), 3.24$ (к, J $6.7 \mathrm{~Hz}, 4 \mathrm{H}$, ${ }^{2} \mathrm{CH}_{2}$ ), 1.72 (ддд, J $13.7 \mathrm{~Hz}, \mathrm{~J} 7.8 \mathrm{~Hz}, \mathrm{~J} 6.3 \mathrm{~Hz}, 4 \mathrm{H}$, 2" $\mathrm{CH}_{2}, \mathrm{M}$ ), 1.55 (ддд, J $13.6 \mathrm{~Hz}, \mathrm{~J} 6.7 \mathrm{~Hz}, \mathrm{~J} 6.6 \mathrm{~Hz}, 4 \mathrm{H}$, $\left.{ }^{3 "} \mathrm{CH}_{2}\right), 1.17-1.35\left(\mathrm{M}, 32 \mathrm{H}, \mathrm{CH}_{2}\right), 0.84(\mathrm{~T}, \mathrm{~J} 6.8 \mathrm{~Hz}, 6 \mathrm{H}$, $\mathrm{CH}_{3}$ ).

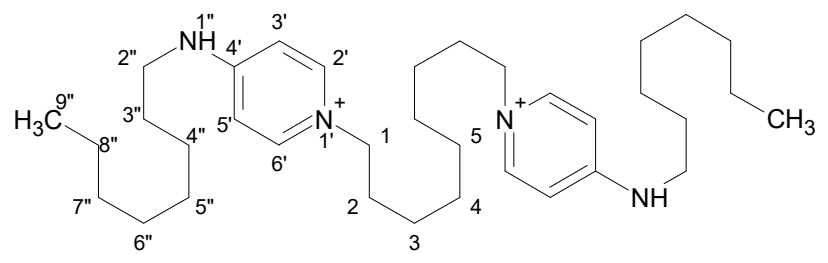

Спектр ${ }^{19} \mathrm{~F}$ ЯМР I, ठ, м.ч.: -135,84 (с, 6F, $\mathrm{SiF}_{6}{ }^{2-}$ ).

Віднесення коливань в ІЧ-спектрі I проведено 3 урахуванням даних $[14,15]$. Валентні коливання $v(\mathrm{NH})$ катіонів і $\mathrm{v}(\mathrm{OH})$ молекул води виявляються в області 3514 - 3000 см$^{-1}$, причому більш високочастотні компоненти в спектрі I пов'язані переважно 3 коливаннями $v(\mathrm{OH})$. Розмитий характер максимумів смуг $v(\mathrm{NH})$ і $v(\mathrm{OH})$ може вказувати на участь груп $\mathrm{NH}$ і молекул води в міжмолекулярних Н-зв'язках. Коливання $v_{a s}\left(\mathrm{CH}_{2}\right), v_{s}\left(\mathrm{CH}_{2}\right)$ і $\delta_{s}\left(\mathrm{CH}_{2}\right)$ метиленових груп чітко ідентифікуються в характеристичних областях при 2928, 2853 і 1463 см$^{-1}$ відповідно, коливання кільця спостерігаються у вигляді трьох смуг поглинання В області 1590 - 1520 см$^{-1}$. Коливання v(SiF) і $\delta\left(\mathrm{SiF}_{2}\right)$ аніонів $\mathrm{SiF}_{6}{ }^{2-}$ виявлені у характеристичних ділянках спектра при 737 і 482, 443 см$^{-1}$ відповідно [15]; інтенсивна розширена смуга $v(\mathrm{SiF})$ може включати також маятникові деорормаційні коливання $\rho\left(\mathrm{CH}_{2}\right)$ катіону.

Розчинність I в хлороформі низька і спектри ЯМР комплексу реєстрували в розчині ДМСО-d6. У спектрі ЯMP ${ }^{19} \mathrm{~F}$ аніону $\mathrm{SiF}_{6}{ }^{2-}$ відповідає синглетний сигнал 3 хім. зсувом $\delta_{F}=-135,84$ м.д., який $€$ характерним для солей аніону $\mathrm{SiF}_{6}{ }^{2-}$ [5-7]. Будь-яких продуктів сольоволізу аніону $\mathrm{SiF}_{6}{ }_{6}^{2-}$ аналогічно описаному в роботі [6] в спектрах яМР ${ }^{19} \mathrm{~F}$ не зафріксовано.

При нагріванні комплекс I піддається дегідратації (ендо-есрект при $t_{0}=97^{\circ} \mathrm{C}, t_{\mathrm{m}}=124^{\circ} \mathrm{C}, \Delta \mathrm{m}_{\text {експ. }}$ $\left.=4,28 \%, \Delta \mathrm{m}_{\text {разр. }}=2,53 \%\right) 3$ подальшим розкладанням (ендо-ефрект при $t_{\mathrm{m}}=419^{\circ} \mathrm{C}, \Delta \mathrm{m}=86,6 \%$ ) і окисленням продуктів розкладання (екзо-есректи при $t_{\mathrm{m}}=$ $\left.537,585^{\circ} \mathrm{C}, \Delta \mathrm{m}=100 \%\right)$.

Спроба встановити ступінь гідролізу сполуки I в 0,001 М водному розчині спектрофотометричним методом аналогічно [5] виявилася невдалою: інтенсивна опалесценція реакційного розчину не дозволила провести відповідні вимірювання.

Висновки. Запропоновано метод синтезу октенідину гексафторосилікату моногідрату шляхом реакції іонного обміну між метанольним розчином октенідину дигідрохлориду і надлишком кремнефтороводневої кислоти. Отриманий гексафторосилікат охарактеризований комплексом спектральних методів, оцінені термохімічні характеристики солі. Вивчення карієспрофілактичної активності і гострої токсичності октенідину гексасрторосилікату $є$ предметом наших подальших досліджень.

\section{СИНТЕЗ ОКТЕНИДИНА ГЕКСАФТОРОСИЛИКАТА - НОВОГО ПОТЕНЦИАЛЬНОГО КАРИЕСПРОФИЛАКТИЧЕСКОГО И АНТИБАКТЕРИАЛЬНОГО АГЕНТА}

\section{В. О. Гельмбольдт, В. Ю. Анисимов, И. О. Шишкин}

Одесский национальный медицинский университет

vgelmboldt@te.net.ua

Цель работы. Осуществить синтез октенидина гексафторосиликата как потенциального кариеспрофилактического и антибактериального препарата.

Материалы и методы. Исходные реагенты, октенидина дигидрохлорид и кремнестороводородная кислот являются коммерчески доступными реактивами. ИК-спектры поглощения регистрировали на спектрофотометре Spectrum BX II FT-IR System (Perkin-Elmer), масс-спектры FAB - на спектрометре VG 7070 (VG Analytical), спектры

ISSN 2312-0967. Фармацевтичний часопис. 2017. № 3 
Синтез біологічно активних сполук Synthesis of biologically active compounds

ЯМР ${ }^{1} \mathrm{H},{ }^{19} \mathrm{~F}$ - на спектрометре Varian Gemini-400. Термогравиметрический анализ проводили на дериватограсре Q-1500 D системы F. Paulik - J. Paulik - L. Erdey.

Результаты и обсуждение. Получен октенидина гексафрторосиликат моногидрат на основе реакции ионного обмена между метанольным раствором октенидина дигидрохлорида и кремнесртороводородной кислотой. Состав и ионное строение синтезированного соединения подтверждены методами ИК-, ЯМР ${ }^{1} \mathrm{H},{ }^{19} \mathrm{~F}-$ спектроскопии, массспектрометрии. Термолиз комплекса сопровождается процессами дегидратации и деструкции с дальнейшим окислением фрагментов катиона.

Ключевые слова: кариеспрофилактические агенты; октенидина гексафторосиликат; синтез; спектральные характеристики.

\title{
SYNTHESIS OF OCTENIDINE HEXAFLUOROSILICATE AS NEW POTENTIAL CARIES PREVENTIVE AND ANTIBACTERIAL AGENT
}

\author{
V. O. Gelmboldt, V. Yu. Anisimov, I. O. Shyshkin \\ Odesa National Medical University \\ vgelmboldt@te.net.ua
}

The aim of the work. The synthesis of octenidine hexafluorosilicate as potential caries preventive and antibacterial agent. Materials and Methods. The starting materials, octenidine dihydrochloride and hexafluorosilicic acid, are commercial sources. The IR-absorption spectra were recorded on a spectrophotometer Spectrum BX II FT-IR System (Perkin-Elmer), FAB mass spectra - on a spectrometer VG 7070 (VG Analytical), ${ }^{1} \mathrm{H}$ and ${ }^{19} \mathrm{~F}$ NMR spectra - on a Varian Gemini-400 spectrometer. Thermogravimetric analysis was performed on a Q-1500 D derivatograph of F. Paulik - J. Paulik - L. Erdey's system.

Results and Discussion. The novel octenidine hexafluorosilicate monohydrate was synthesized via ionic exchange reaction between octenidine dihydrochloride in methanol solution and hexafluorosilicic acid. The composition and ionic structure of synthesized compound were confirmed by IR-, ${ }^{1} \mathrm{H},{ }^{19} \mathrm{~F}$ NMR spectroscopy, mass-spectrometry. The thermolysis of complex is accompanied by processes of dehydration and destruction with further oxidation of cation fragments.

Key words: caries preventive agents; octenidine hexafluorosilicate; synthesis; spectral data.

\section{Список літератури}

1. Ten Cate J. M. Contemporary perspective on the use of fluoride products in caries prevention / J. M. ten Cate // Brit. Dental J. 2013. - Vol. 214, № 4. - P. 161-167.

2. Ammonium hexafluorosilicate elicits calcium phosphate precipitation and shows continuous dentin tubule occlusion / T. Suge, A. Kawasaki, K. Ishikawa [et al.] // Dent. Mater. 2008. - Vol. 24, № 2. - P. 192-198.

3. Effect of ammonium hexafluorosilicate application for arresting caries treatment on demineralized primary tooth enamel / Y. Hosoya, K. Tadokore, H. Otani [et al.] // J. Oral Science. - 2013. - Vol. 55, № 2. - P. 115-121.

4. Effects of different antibacterial agents on enamel in a biofilm caries model / S. Savas, E. Kucukyılmaz, E. U. Celik, M. Ates // J. Oral Science. - 2015. - Vol. 57, № 4. - P. 367-372.

5. Preparation, structure and properties of pyridinium/bipyridinium hexafluorosilicates / V. O. Gelmboldt, Ed. V. Ganin, M. M. Botoshansky [et al.] // J. Fluorine Chem. - 2014. Vol. 160, № 4. - P. 57-63.

6. Gelmboldt V. O. Hexafluorosilicates with antibacterial active guanidine containing cations / V. O. Gelmboldt, V. Yu. Anisimov, O. V. Prodan // News of Pharmacy. - 2014. - № 3 (79). - P. 42-45.

7. Gelmboldt V. O. Synthesis and characterization of cetylpyridinium hexafluorosilicate as new potential caries protecting agent / V. O. Gelmboldt, O. V. Prodan, V. Yu. Anisimov // Am. J. PharmTech. Res. - 2014. - Vol. 4, № 6.
- P. 513-521.

8. Оценка кариеспрофилактической эфрфективности «ониевых» гексафрторосиликатов в эксперименте / В. В. Лепский, В. Ю. Анисимов, О. В. Продан, В. О. Гельмбольдт // Вісник стоматології. - 2015. - № 2. - С. 10-13.

9. Анисимов В. Ю. Кариеспрофилактическая эфрфективность и безвредность разных доз цетилпиридиния гексафторосиликата / В. Ю. Анисимов, В. О. Гельмбольдт, А. П. Левицкий // Одеський мед. журн. - 2016. - № 2(154). - С. 12-16.

10. Eley B. M. Antibacterial agents in the control of supragingival plaque - a review / B. M. Eley // Brit. Dent. J. 1999. - Vol. 186, № 6. - P. 286-296.

11. Assadian O. Octenidine dihydrochloride: chemical characteristics and antimicrobial properties / O. Assadian // J. of Wound Care. - 2016. - Vol. 25, № 3. - P. S3-S6.

12. Климова В. А. Основные микрометоды анализа органических соединений / В. А. Климова. - М. : Химия, 1975. - 224 с. 13. Мышляева Л. В. Аналитическая химия кремния/Л.В.Мышляева, В. В. Краснощеков. - М. : Наука, 1972. - 212 с.

14. Pretsch E. Structure determination of organic compounds. Tables of spectral data / E. Pretsch, P. Bühlmann, M. Badertscher. - Berlin: Springer, 2009. - 433 p.

15. Nakamoto K. Infrared and raman spectra of inorganic and coordination compounds / K. Nakamoto. - New York: Wiley, 1986. - 484 p. 
Синтез біологічно активних сполук

Synthesis of biologically active compounds

\section{References}

1. Ten Cate JM. Contemporary perspective on the use of fluoride products in caries prevention. Brit Dental J. 2013;214: 161-167.

2. Suge T, Kawasaki A, Ishikawa K, Matsuo T, Ebisu K. Ammonium hexafluorosilicate elicits calcium phosphate precipitation and shows continuous dentin tubule occlusion. Dent Mater. 2008;24: 192-198.

3. Hosoya Y, Tadokore K, Otani H, Hidaka K, Inoue T, Miyazaki $\mathrm{M}$, et al. Effect of ammonium hexafluorosilicate application for arresting caries treatment on demineralized primary tooth enamel. J. Oral Science. 2013;55: 115-121.

4. Savas S, Kucukyılmaz E, Celik EU, Ates M. Effects of different antibacterial agents on enamel in a biofilm caries model. J. Oral Science. 2015;57: 367-372.

5. Gelmboldt VO, Ganin EdV, Botoshansky MM, Anisimov VYu, Prodan OV, Kravtsov VCh et al. Preparation, structure and properties of pyridinium/bipyridinium hexafluorosilicates. J. Fluorine Chem. 2014;160: 57-63.

6. Gelmboldt VO, Anisimov VYu, Prodan OV. Hexafluorosilicates with antibacterial active guanidine containing cations. News of Pharmacy. 2014;3(79): 42-45.

7. Gelmboldt VO, Anisimov VYu, Prodan OV. Synthesis and characterization of cetylpyridinium hexafluorosilicate as new potential caries protecting agent. Am J PharmTech. Res. 2014;4: 513-521.
8. Lepskiy VV, Anisimov VYu, Prodan OV, Gelmboldt VO. [Experimental evaluation of caries preventive efficiency "onium" hexafluorosilicates]. Visnyk stomatolohii. 2015;2: 10-13. Ukrainian.

9. Anisimov VYu, Levitsky AP, Gelmboldt VO. [Cariespreventive efficacy and safety of different doses of cetylpyridinium hexafluorosilicate]. Odeskyi medychnyi zhurnal. 2016;2(154): 12-16. Ukrainian.

10. Eley BM. Antibacterial agents in the control of supragingival plaque - a review. Brit. Dent. J. 1999;186: 286-296. 11. Assadian O. Octenidine dihydrochloride: chemical characteristics and antimicrobial properties. J of Wound Care. 2016;25: S3-S6.

12. Klimova VA. Main micromethods of analysis of organic compounds. [Основные микрометоды анализа органических соединений] Moscow: Khimiya, 1975. Russian.

13. Myshlyaeva LV, Krasnoshchekov VV. Analytical chemistry of silicon. [Аналитическая химия кремния] Moscow: Nauka, 1972. Russian.

14. Pretsch E, Bühlmann P, Badertscher M. Structure determination of organic compounds. Tables of Spectral Data. Berlin: Springer, 2009.

15. Nakamoto K. Infrared and raman spectra of inorganic and coordination compounds. New York: Wiley, 1986.

Отримано 22.06.2017 